\title{
THE DEMONSTRATION OF INTRAVASCULAR HAEMO- LYSIS BY MEANS OF SERUM PAPER ELECTROPHORESIS AND A MODIFICATION OF SCHUMM'S REACTION
}

BY

\author{
F. C. NEALE, G. M. ABER, AND B. E. NORTHAM \\ From the Departments of Biochemistry and Clinical Pathology, Queen Elizabeth Hospital, Birmingham, \\ and the Department of Biochemistry, General Hospital, Birmingham
}

(RECEIVED FOR PUBLICATION OCTOBER 10, 1957)

In studying the pathogenesis of anaemia associated with many clinical disorders one is often confronted with the problem of whether intravascular haemolysis is taking place. Haemolysis may result either from an intrinsic abnormality of the red cell, rendering it of shorter life span than normal, and this may be of an hereditary or acquired nature, or, alternatively, from the presence of some plasma factor capable of inducing lysis.

Plasma factors producing lysis result from certain types of poisoning, toxic effects of drugs, and many generalized infections. Haemolysis may also occur as a result of renal or hepatic failure and in other metabolic disorders. The exact mechanism of the haemolysis in these conditions, although unknown, is probably also attributable to plasma factors. Despite the wide range of known causative factors many cases of haemolysis remain unclassified, e.g., those which are seen in the reticuloses and other neoplastic states.

In patients manifesting an extreme degree of haemolysis, extracorpuscular haemoglobin can be seen in the serum, which, if in sufficient concentration, is excreted into the urine. More commonly an increased rate of haemolysis is manifest by a raised serum bilirubin level and an increased excretion of urobilinogen in the urine and faeces. Reticulocytosis, if present in such circumstances, reflects a compensatory hyperplasia of the bone marrow, but both these latter diagnostic features may be partially obscured should the rate of bilirubin production be matched by the ability of the liver to excrete it, or should some complicating factor, such as uraemia or chronic infection, simultaneously depress erythropoietic activity. Under these conditions even moderate haemolysis may escape detection by existing routine laboratory procedures, and in the present work two new complementary techniques are described which appear to be more sensitive than other simple procedures, and can demonstrate that haemolysis is occurring or has recently taken place. These tests depend on showing an altered pattern of haemoglobin attachment to the serum proteins. One technique employs paper electrophoresis of serum with subsequent differential staining of the strips to show the position of the protein bands relative to the haemoglobin pigments, and the other technique is based on a variation of the Schumm haemochromogen reaction (Schumm, 1912), in which the haemoglobin itself is involved.

The Schumm reaction, as normally performed, allows detection of methaemalbumin in much lower concentration than is possible by direct spectroscopic examination (Fairley, 1941). The presence of methaemalbumin in serum is indicative of intravascular haemolysis, of which the occasional occurrence in pernicious anaemia argues for a significant haemolytic component in that disease. The common finding of raised serum bilirubin levels in patients with the disease points to a similar conclusion, and it appeared possible that closer examination of such sera and specimens from other patients in whom haemolysis was occurring or suspected might yield information concerning the severity of the haemolytic process, and its response to therapy in relation to the patients' haematological and clinical progress.

\section{Clinical Material}

Cases studied included 10 cases of untreated pernicious anaemia, five cases of untreated $\stackrel{\mathcal{P}}{\rightarrow}$ megaloblastic anaemia associated with folic acid deficiency, nine cases of haemolytic anaemia of varying aetiology, three patients with evidence of minor blood transfusion reaction, and three cases of uraemia associated with anaemia in which haemolysis was suspected. In addition, tests were 
performed on 18 patients with various pathological conditions, with or without anaemia, but in whom no haemolytic component was suspected. A control group of 30 sera from healthy individuals was also similarly investigated. As the underlying mechanism of the reaction became clearer an attempt was made to characterize further the implicated proteins. Tests were made involving urinary proteins from patients with nephrosis and a serum albumin fraction as supplied for transfusion purposes by the Lister Institute.

\section{Experimental}

Preparation of Haemoglobin Solution.-A stock solution of haemoglobin was obtained by lysing a known volume of washed normal red cells with an equal volume of distilled water followed by freezing and thawing to give an approximate concentration of $15 \mathrm{~g}$. haemoglobin $/ 100 \mathrm{ml}$. representing a dilution of 1 in 2 . This solution may be preserved in the frozen state for several weeks.

Addition of Haemoglobin Solution to Test Serum.Haemoglobin concentrations of approximately 0.3 , 0.6 , and $1.2 \mathrm{mg}$. $/ \mathrm{ml}$. serum were obtained by the addition of $1 \mathrm{ml}$. test serum to $0.002,0.004$, and $0.008 \mathrm{ml}$. of the stock haemoglobin solution. This gives haemoglobin dilutions in serum equivalent to 1 in $1,000,1$ in 500 , and 1 in 250 of the concentration normally present in packed red cells. A further $1 \mathrm{ml}$. serum was placed in a fourth tube to which no haemoglobin was added.

Although with practice these volumes were found to be adequate for spectroscopic examination in a Hartridge reversion spectroscope, double quantities are more convenient if the specimen permits.

Paper Electrophoresis of Test Serum.-Samples of each of the above sera, with and without added haemoglobin, after standing for $\mathbf{3 0}$ minutes at room temperature were subjected to electrophoretic separation on filter paper. Most separations were carried out on an apparatus of the "hanging-strip " type (Neale, 1955) using $0.05 \mathrm{ml}$. serum on Whatman No. 100 filter paper. The remainder were performed on an E.E.L. horizontal type apparatus using $0.02 \mathrm{ml}$. serum on Whatman No. 3MM paper. All separations were allowed to run for 16 to 18 hours at room temperature. Barbitone buffers of $p \mathrm{H} 8.6$ were employed, as described by Durrum (1950) for the hanging type apparatus, and according to the formula in the manufacturer's handbook for the E.E.L. apparatus $\left(30 \mathrm{~g}\right.$. sodium barbitone, $19.5 \mathrm{~g}$. $\mathrm{CH}_{3} \mathrm{COONa}$. $3 \mathrm{H}_{2} \mathrm{O}, 205 \mathrm{ml}$. $0.1 \mathrm{~N} \mathrm{HCl}$, made up to 3 litres with distilled water). After electrophoresis the strips were dried at $100^{\circ} \mathrm{C}$. and then cut longitudinally into two equal parts, one half stained for proteins with bromphenol blue and the other half retained for subsequent spraying with benzidine reagent to show the positions of haemoglobin or haem-containing pig. ments relative to the protein fractions.
Preparation of Haematin Solutions.-Haemin was prepared from human red cells according to the method described by Gattermann (1941). A solution of alkaline haematin was prepared freshly as required, by dissolving $10 \mathrm{mg}$. of this material in $10 \mathrm{ml}$. N/10 $\mathrm{NaOH}$ and diluting to $100 \mathrm{ml}$. with water as soon as solution was achieved. Portions of this dilute solution $(0.1 \mathrm{mg}$. $/ \mathrm{ml}$.) were added to $2 \mathrm{ml}$. portions of serum, giving final concentrations up to $10 \mu \mathrm{g}$. haematin $/ \mathrm{ml}$. serum. Electrophoresis of these mixtures was carried out as described above.

Benzidine Reagent.-This was prepared by adding $1 \mathrm{ml}$. of 20 volumes hydrogen peroxide to $30 \mathrm{ml}$. of a saturated solution of benzidine (extra pure for blood testing, B.D.H.) in glacial acetic acid. This ratio of peroxide to benzidine was found to give optimum sensitivity with minimal background discoloration. The mixed reagent was applied without delay to the half-strips by means of an all-glass spray, when an intense blue colour developed within a few seconds in the presence of haemoglobin or its haem-containing derivatives. This blue colour changes over the next few minutes to a blue-black, and the background, initially white, becomes light brownish-yellow. If a permanent record is desired the strip should be photographed as soon as possible after staining. In place of benzidine, which is now becoming difficult to obtain in a highly purified state because of its reported carcinogenic properties, $o$-tolidine may be used. The reagent prepared as described by Kohn and O'Kelly (1955), namely equal parts of a $4 \%$ ethanolic solution of $o$-tolidine, glacial acetic acid, and water, to which is added a $\frac{1}{4}$ volume of 20 volumes hydrogen peroxide, gives results similar to the benzidine spray, but the colour fades rather more quickly.

Schumm Reaction. - After samples have been removed for electrophoresis the four sera were covered with a layer of ether and $0.1 \mathrm{ml}$. AnalaR ammonium sulphide added to each as recommended by Fairley (1941). They were then examined in a Hartridge reversion spectroscope. In the presence of methaemalbumin a positive Schumm test is indicated by the appearance of a sharp band at $558 \mathrm{~m} \mu$; a weaker band at $530 \mathrm{~m} \mu$ may also be seen. However, when haemoglobin is involved in the production of the haemochromogen the $558 \mathrm{~m} \mu$ band only is seen.

Procedure for Urine--Haemoglobin dilutions of 1 in $4,000,1$ in $2,000,1$ in 1,000 , and 1 in 500 in urine were made and $0.2 \mathrm{ml}$. samples taken for electrophoresis; otherwise procedures were as for serum.

\section{Results}

Electrophoretic Behaviour of Haemoglobin and Haematin in Normal Sera.- In the absence of any slight haemolysis introduced during the taking of the blood or separation from the cells, normal serum is spectroscopically clear and no blue colour appears on spraying the electrophoretic strip with benzidine reagent. However, such slight haemo- 


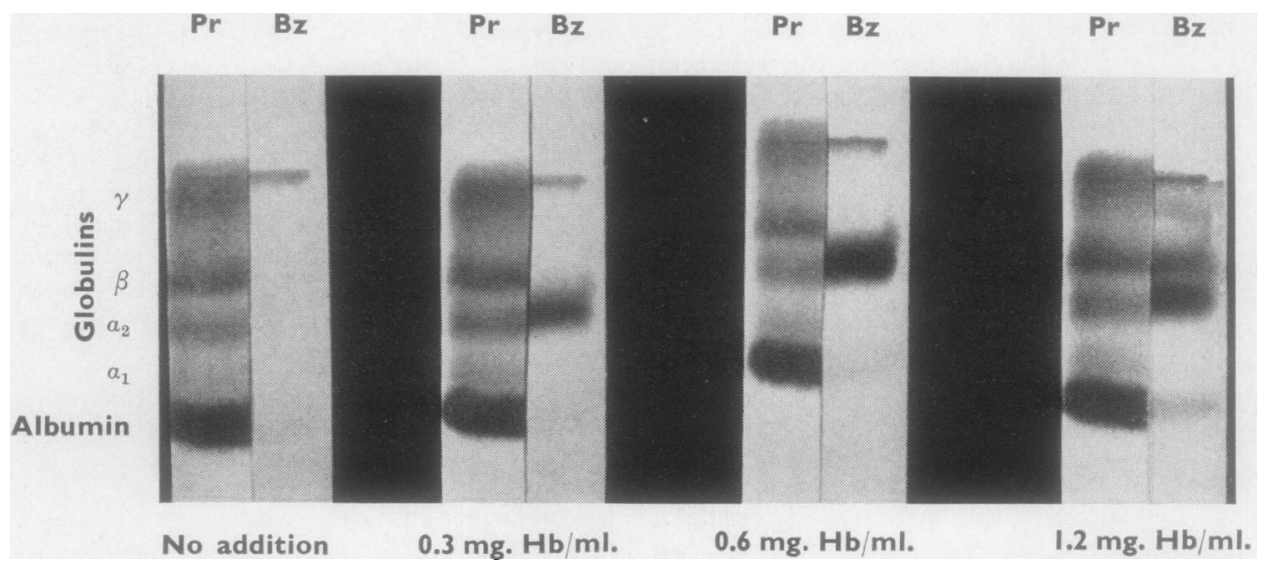

lysis is not always possible to avoid, even when the utmost care is taken, viz., permitting the blood to flow freely through a large needle (18 s.w.g.) without the use of a syringe, and allowing an adequate time for good clot retraction. When sufficient haemolysis occurs to permit the alpha band of oxyhaemoglobin to be just discernible spectroscopically in a $16 \mathrm{~mm}$. test-tube, then the sprayed strip develops a diffuse blue band between the $\alpha_{2}$ and $\beta$ globulins. Occasionally this rather faint band is seen directly in line with the $\alpha_{2}$ fraction. On deliberately adding the two lower haemoglobin concentrations defined above to most normal sera a progressive intensification of this diffuse band is seen. When the highest concentration, 1 in 250 , is reached, however, this benzidine-staining band is seen to have two components, one in a position similar to the above, and the other, a slower moving band, corresponds to the faster moving $\beta$ globulin fraction. At this concentration, too, a third though much less intense band may also be seen opposite the albumin and a diffuse trail of haemoglobin becomes apparent behind the $\beta$ globulins extending back to the origin (Fig. 1). This composite pattern appears to reflect the over-saturation of the haemoglobincarrying mechanism of normal serum, but in certain of the control sera, where the $\alpha_{2}$ globulin appeared unusually high, separation into two bands did not occur but a further intensification of the single band was seen. On the other hand, in a few instances the appearance of a $\beta$ globulin band began at a dilution of 1 in 500 , although these were comparatively rare occasions.

Paper electrophoresis of haemoglobin solutions in saline at similar concentrations exhibited only a trail, quite dissimilar to the discrete bands obtained in the presence of serum. Coating the $\vec{\theta}$ filter paper with protein by pre-running serum or $\mathcal{G}$ an albumin transfusion preparation before apply- $\odot$ ing the haemoglobin solutions did not materially alter this trail and did not produce the characteristic pattern seen when haemoglobin and serum $\overline{0}$ are mixed before electrophoresis. The absence of this trail must indicate a firm combination with $\stackrel{\varnothing}{\triangle}$ protein fractions which protects the haemoglobin $\overrightarrow{\vec{A}}$ from adsorption on to the paper (Fig. 2).

The binding of haematin to serum proteins was similarly studied, and it was found to be carried almost equally by the albumin and the leading $\beta$ globulin fractions (Fig. 3). A similar result was? reported by Fiser-Herman and Davorin (1953) $\frac{0}{3}$ with haematin prepared by alkali denaturation of haemoglobin, although they found haematin pre-응 pared from haemin was bound to $\alpha_{2}$ globulin. Serum to which haematin had been added showed음 an absorption band at $624 \mathrm{~m} \mu$ when examined in the spectroscope.

Schumm Reaction Applied to Normal Serum.- N Schumm (1912) considered his test to identify haematin, but Fairley (1941) interpreted a positive Schumm reaction as indicative of methaem- $\omega$ albumin in the serum under examination. In non-haemolysed normal serum no absorption bands are seen following this reaction, whereas in sera to which small additions of haemoglobin ${ }^{+}$ have been made (dilutions of 1 in 1,000 and 1 in $\frac{0}{\circ}$ 500 ) the broad but rather faint band of reduced $\stackrel{\oplus}{\mathbb{D}}$ haemoglobin can be seen. This reverts to the double-banded oxyhaemoglobin spectrum on@ gently shaking with air, but the reduced spectrum returns on further standing. At the highest con- $?$ 


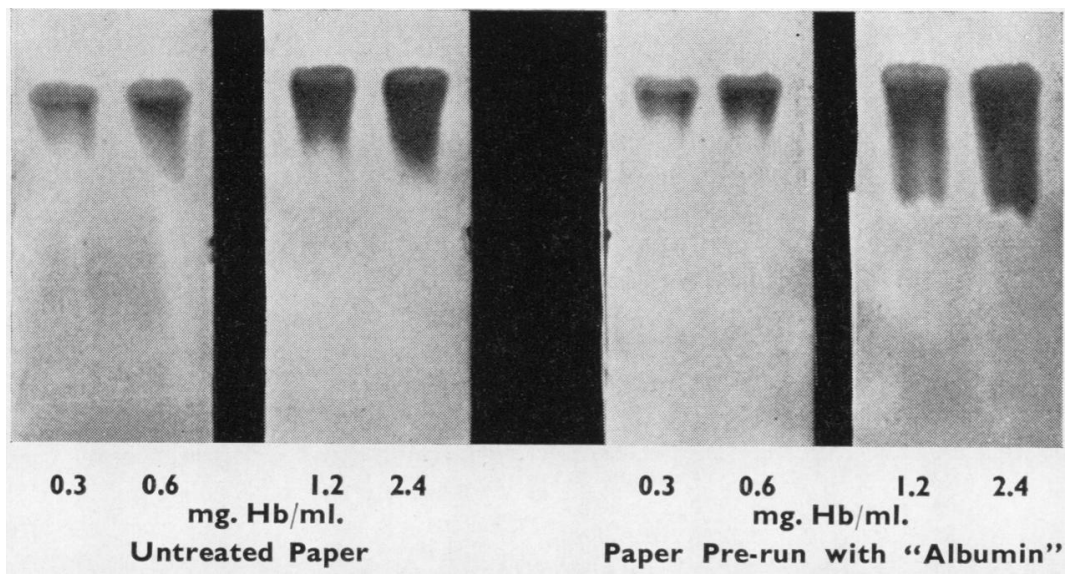

FIG. 2.-Electrophoresis of haemoglobin on albumin-coated and untreated paper. In the concentrations used $\mathrm{Hb}$ is clearly visible only after benzidine spraying and does not form a discrete band but is adsorbed on to filter paper whether or not this has been first " carpeted " with albumin.

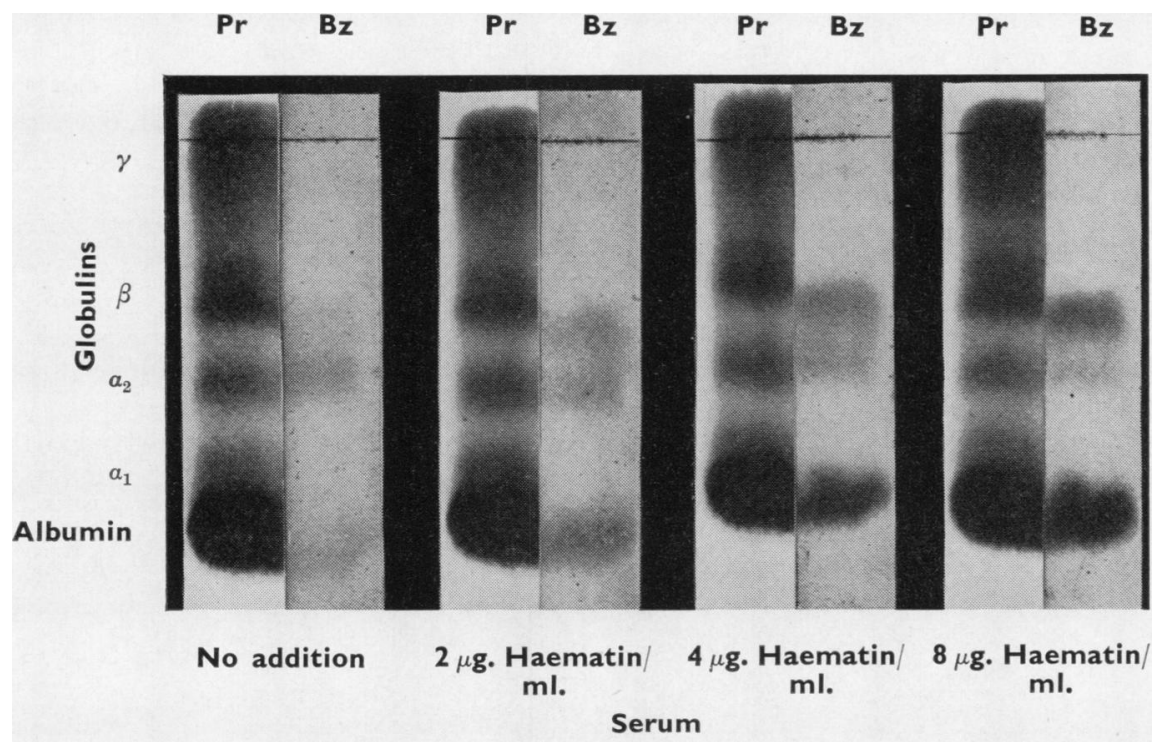

FIG. 3.-Electrophoresis of normal serum to which haematin has been added. Haematin is taken up by both albumin and $\beta$ globulin. A small quantity of haemoglobin is present in this serum and migrates with the haptoglobin.

centration $(1.2 \mathrm{mg} . / \mathrm{ml}$.) of haemoglobin this band may merely be intensified, but in some sera a new sharper and denser band at $558 \mathrm{~m} \mu$ slowly appears through the centre of the reduced haemoglobin. More occasionally this band has been observed at the next lower concentration also, viz., $0.6 \mathrm{mg}$./ $\mathrm{ml}$. Reversion to the oxyhaemoglobin spectrum takes place on shaking in this case too, but ultimately a stage is reached when the $558 \mathrm{~m} \mu$ band is permanent and irreversible.

Although this band appears at the same wavelength as in the classical Schumm reaction, it does not seem to represent the same haemochromogen because its reversible replacement by the oxyhaemoglobin spectrum shows clearly that its origin is not methaemalbumin, but that it derives indirectly from haemoglobin. The production of methaemalbumin by the incubation of haemoglobin with serum for two days was reported by Fairley and Bromfield (1937), but the haemochromogen now described appears within minutes and under entirely different conditions. The authentic Schumm reaction given by serum to which haematin has been added in vitro differs 
also by appearing even more promptly and giving two absorption bands. These bands can also be caused to fade and reappear for a time by shaking, but no alternative bands take their place. The limiting concentration of haematin in serum that could be detected by paper electrophoresis, which required only $0.02-0.05 \mathrm{ml}$. serum, was $1 \mu \mathrm{g}$. per ml. By Schumm's test when viewed in a $16 \mathrm{~mm}$. test-tube, which needs at least $1 \mathrm{ml}$. serum, it was $2 \mu \mathrm{g}$. per $\mathrm{ml}$. Thus, not only has the electrophoretic technique about twice the ultimate sensitivity of spectroscopy but it will also give reliable results with a very much smaller specimen.

Electrophoretic Behaviour of Haemoglobin and Haematin in Sera from Patients with Haemolysis.-Haemolysis may present as an acute severe episode or may exist in a milder and chronic form upon which a more severe phase may be superimposed. Differing electrophoretic patterns reflect these varying degrees of lysis. In patients experiencing an acute haemolytic crisis a large quantity of methaemalbumin is usually identifiable directly by its absorption band at $624 \mathrm{~m} \mu$ and these sera may also contain free haemoglobin in varying amount. The urine may contain haemoglobin and methaemoglobin if the threshold level is exceeded. Such urines on electrophoresis may be found to contain other serum protein fractions whose disappearance coincides with that of the haemoglobin pigments. Their presence indeed may be due to competition for reabsorption by the latter in the tubules (cf. Hardwicke and
Squire, 1955) rather than the result of any transient kidney damage. In one such case of paroxysmal cold haemolysis this cycle could be provoked at will by immersing the patient's feet and legs in cold water for a short period. Urines of this type show a strongly positive benzidinestaining albumin, but, for reasons discussed later, this alone is not necessarily evidence for the presence of methaemalbumin although indeed it may well be present as was claimed by Hensley and Blackburn (1953). These sera from cases showing acute haemolysis after electrophoresis and benzidine spraying give an intense blue reaction in the albumin area and there may also be a much weaker band on the leading edge of the $\beta$ globulins. Behind this latter band a trail of haemoglobin may be seen (Fig. 4). If haemoglobin is added in vitro to these sera, the only visible result is that this trail intensifies and spreads forwards as seen when haemoglobin in increasing concentrations is itself subjected to electrophoresis (see Fig. 2). In addition to the case of paroxysmal cold haemoglobinuria mentioned above, this type of acute phase was observed in one patient suffering from acquired haemolytic anaemia of the immunological type and in two patients with pernicious anaemia.

Examination of sera from patients in whom chronic haemolysis of lesser degree has been occurring reveals a modification of this pattern, in which the benzidine-positive material in the albumin band is diminished whereas that in the $\beta$ globulin region is increased, and when haemo-

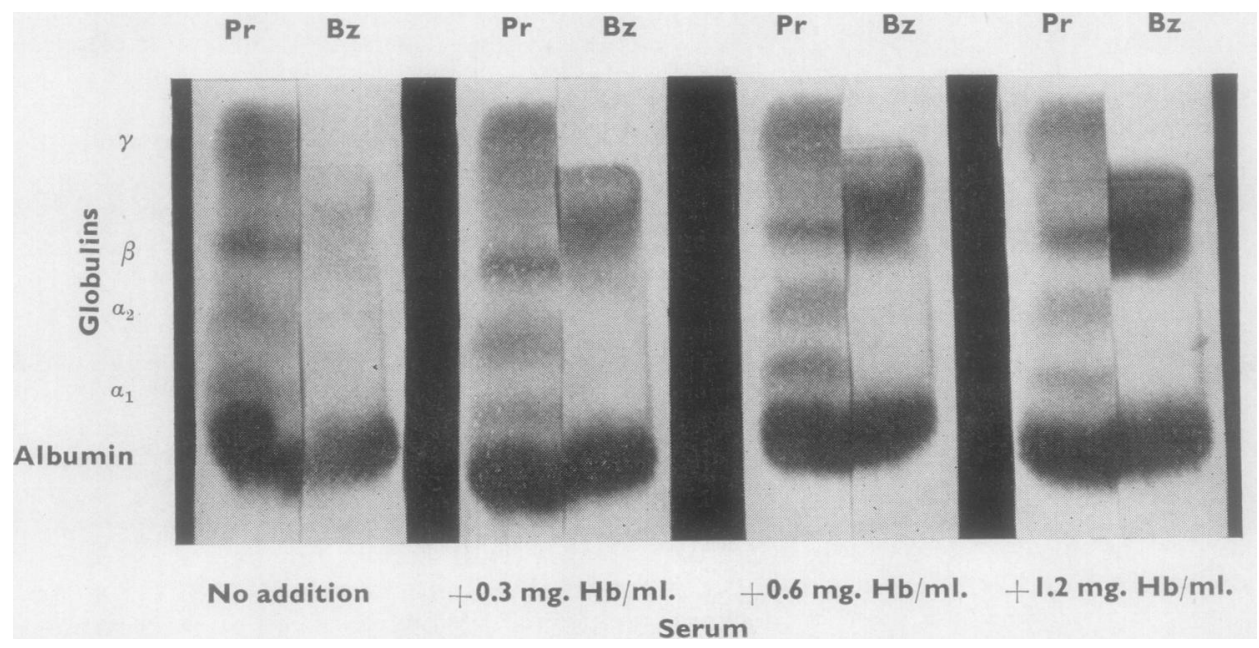

FIG. 4.-Position, after electrophoresis, of haemoglobin added to serum from a patient with acute haemolysis. In this case methaemalbumin is found, but neither haptoglobin or Hb-binding $\beta$ globulin is demonstrable, added Hb combining with the albumin and also leaving a trail. 
globin is added to these sera this difference is further emphasized. Simultaneously the staining intensity of albumin, $\beta$ globulin, and the haemoglobin trail is increased (Fig. 5a). In some cases, where haemolysis introduced during the collection of the specimen is minimal, the pattern after electrophoresis is normal, and it is not until the first haemoglobin addition is made that an abnormal picture appears (Fig. 5b). Examples of this type have occurred in cases of familial acholuric jaundice, mild transfusion reaction, acquired haemolytic anaemias of various types, including those associated with the collagen disorders and the reticuloses, anaemias associated with the uraemic state, as well as in pernicious anaemia and megaloblastic anaemias associated

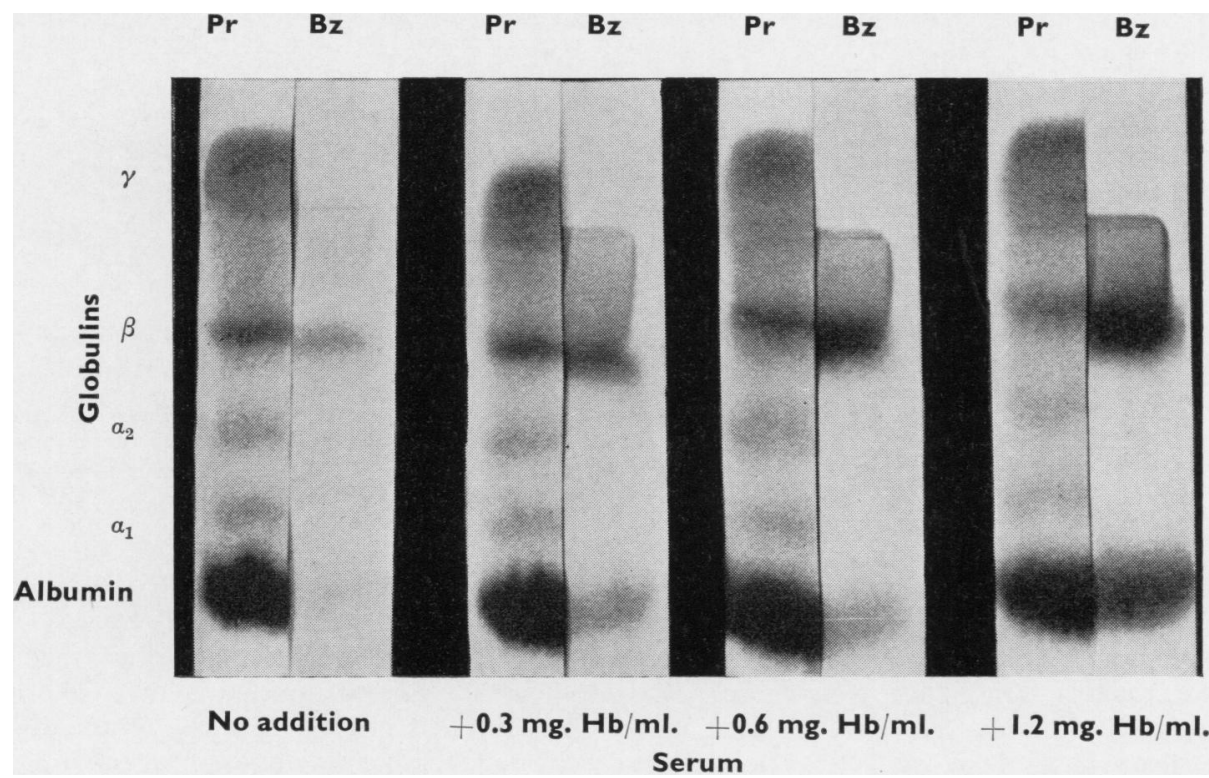

FIG. 5 (a).-Mode of attachment of added haemoglobin to sera from patients with chronic haemolysis. No haptoglobin is seen in this serum, haemoglobin being bound only to $\beta$ globulin and albumin.

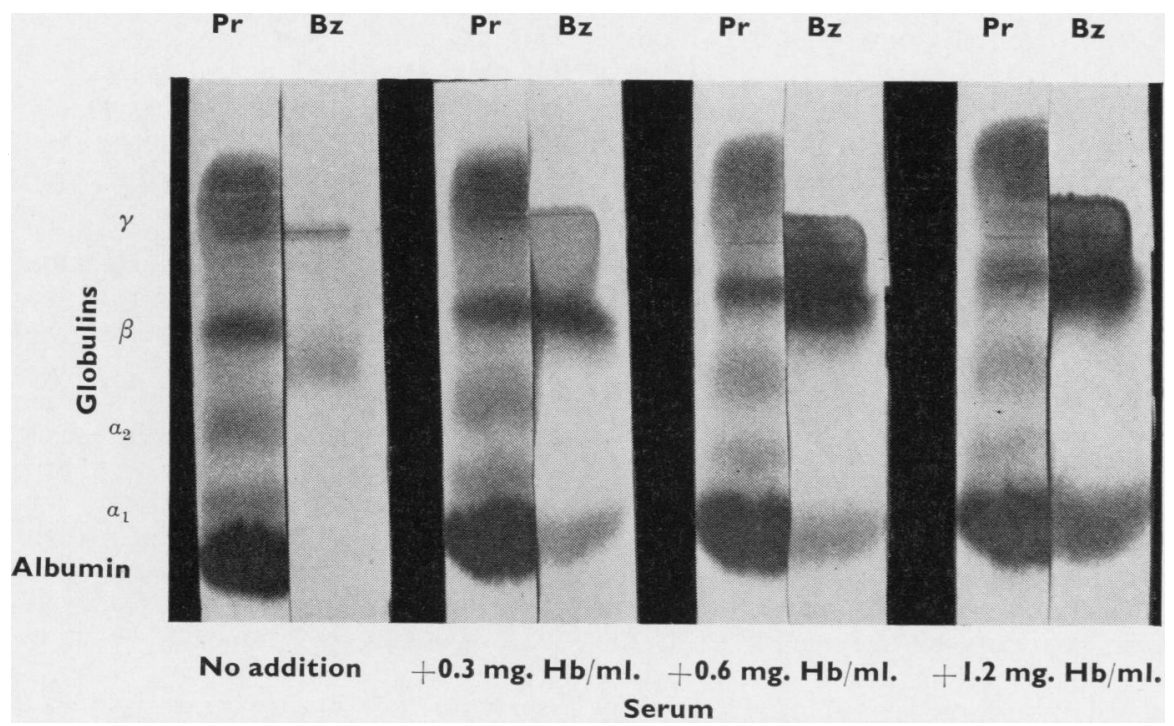

FrG. 5 (b).-A minimal quantity of haptoglobin is present in this serum: added haemoglobin is attached only to $\beta$ globulin and albumin. 


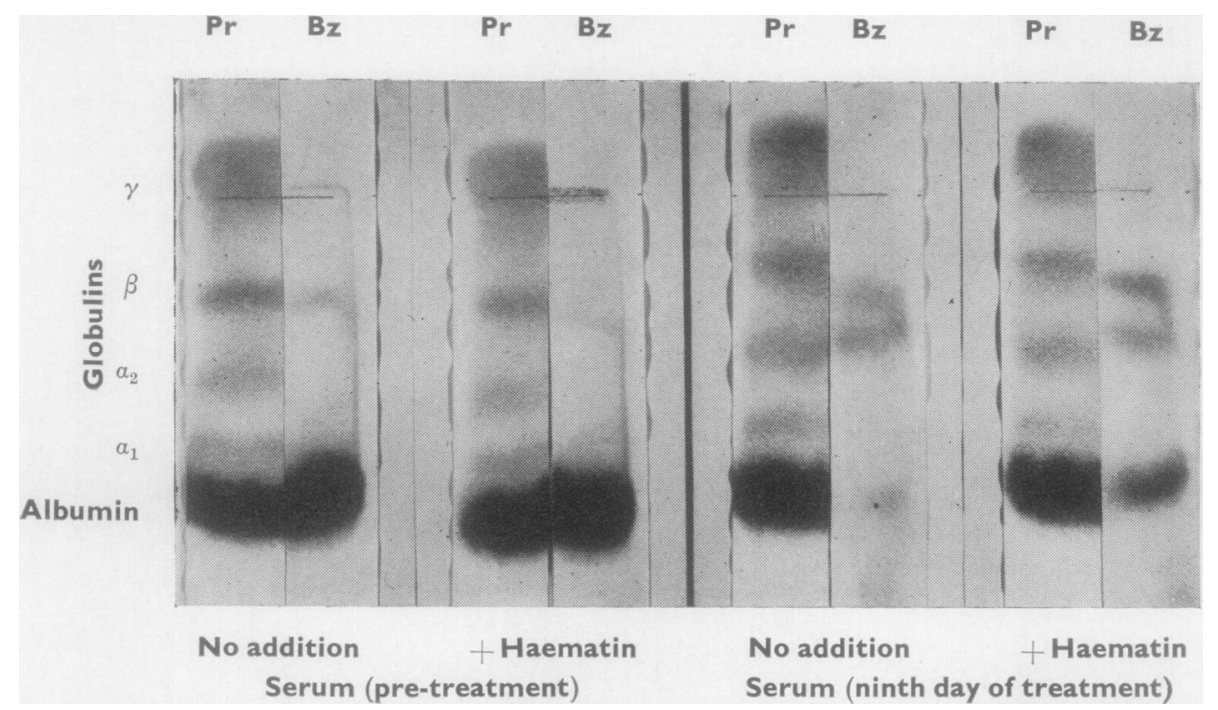

FIG. 6.-Return of haematin-binding $\beta$ globulin to serum of patient with pernicious anaemia nine days after the start of vitamin $B_{12}$ therapy. The serum, taken initially during an acute haemolytic phase, shows a very strong methaemalbumin band, but will not accept haematin into the $\beta$ globulins. On the ninth day of treatment methaemalbumin has disappeared, a little haemoglobin is present, and is seen to be bound to both haptoglobin and $\beta$ globulin. Added haematin is now accepted by $\beta$ globulins as well as by albumin.

with folic acid deficiency. In many of these instances routine laboratory procedures had failed to demonstrate any evidence of an active haemolytic process. In addition to these pathological conditions, similar results were seen when cord blood was examined, reflecting the physiological haemolysis of the newborn.

The acceptance of haematin by sera of these groups also differs according to the severity of the attack. Its pattern of attachment to the albumin and $\beta$ globulin fractions parallels their ability to bind haemoglobin ; thus in the most severe cases, where both the $\alpha_{2}$ and $\beta$ globulin binding fraction had disappeared, the addition of haematin resulted in uptake by the albumin alone. This points to the probability of common binding sites in both albumin and $\beta$ globulin for haematin and haemoglobin (Fig. 6). By following the progress of patients with pernicious anaemia under treatment with vitamin $B_{12}$ the simultaneous return of the ability of the $\beta$ globulin to bind both haematin and haemoglobin has been seen.

Schumm Reaction Applied to Sera from Patients with Haemolysis. - The character of the Schumm reaction in these sera was found to be dependent on the presence of methaemalbumin or quite small amounts of haemoglobin. If the former were present the haemochromogen spectrum described by Schumm (1912) and later by Fairley (1941) was at once obtained. However, in many cases where haemolysis was suspected this reaction was negative, and it was only after deliberately adding haemoglobin that a haemo- 응 chromagen band appeared, although rather more slowly, a band at $558 \mathrm{~m} \mu$ gradually replacing the reduced haemoglobin spectrum. This reaction has already been described as occurring in normal serum containing the higher haemoglobin concentrations, but in these abnormal sera the lowest con- $\frac{\overline{0}}{8}$ centration will invariably bring it about. At a 0 haemoglobin dilution of 1 in 500 the band intensifies, but at 1 in 250 , although still darker, its $ᄋ$ demarcation is a little less precise due to the broad absorption band of reduced haemoglobin with which its edges merge.

Influence of Therapy on Haemoglobin Distribution in Serum.- In order to follow the return N to normal of the electrophoretic behaviour and Schumm reaction, a study of the influence of $\mathcal{N}$ therapy with vitamin $B_{12}$ in patients suffering $\omega$ from pernicious anaemia was chosen, as in this condition a good response to therapy could bece confidently anticipated. For the same reason the progress of another group of patients with non-? Addisonian megaloblastic anaemia responding to $\frac{7}{7}$ folic acid therapy was also followed. Both tests had always been found to be either normal or abnormal for any given serum, and further㐫 evidence that both were related to one commono mechanism in haemoglobin carriage arose from 
the simultaneous changes they underwent in response to therapy. This sequence of change may be illustrated by reference to the following case.

D. A., a woman aged 56, was admitted to hospital as a medical emergency. She had a slight icterus, severe anaemia, and was mentally confused. Apart from a systolic cardiac murmur, slight ankle oedema, and the spleen being just palpable, there was no other noteworthy clinical finding.

Blood examination showed severe macrocytic anaemia: Hb $36 \%$ (5.3 g.\%), R.B.C.s $1.03 \mathrm{~m}$. per c.mm., P.C.V. $12 \%$, M.C.V. $116 \mathrm{c} \mu$, reticulocytes $4.8 \%$. Blood films showed features consistent with a diagnosis of pernicious anaemia. The bone marrow was megaloblastic and there was histamine-fast achlorhydria. The indirect van den Bergh reaction was positive, serum bilirubin was $2.4 \mathrm{mg} . / 100 \mathrm{ml}$, Schumm's test was positive; fasting serum iron $182 \mu \mathrm{g} . / 100 \mathrm{ml}$. and iron-binding capacity $230 \mu \mathrm{g}$./ $100 \mathrm{ml}$. Osmotic and mechanical fragility tests on the red cells were within normal limits and the direct Coombs test was negative.

Treatment with daily intramuscular injections of $100 \mu \mathrm{g}$. vitamin $B_{12}$ was instituted, and within two days there was striking clinical improvement. Biochemically the first change noted was a sharp fall in serum iron to $20 \mu \mathrm{g}$. $/ 100 \mathrm{ml}$. 48 hours after treatment was started (Hawkins, 1955). On the fifth day of treatment the serum bilirubin had fallen to $0.5 \mathrm{mg}$./ $100 \mathrm{ml}$., reticulocytes had risen to $28.5 \%$. On the seventh day the Schumm test was negative.

Studies of the electrophoretic pattern during the recovery phase revealed a gradual loss of benzidine- staining pigments in the albumin region and these had entirely disappeared by the seventh day, the same day as the Schumm test became negative. After haemoglobin addition the band in the $\beta$ globulin region gradually became more intense, but there was no uptake of haemoglobin in the $\alpha_{2}$ globulin area until the ninth day of treatment, and even then the ability of this fraction of the $\alpha_{2}$ globulin to carry haemoglobin was far from normal, and remained so until the eleventh day of treatment (Fig. 7).

The absence of any haemoglobin binding in the $\alpha_{2}$ and the minimal uptake in the $\beta$ globulin region suggest that in this patient haemolysis had played a major role in the production of such a severe degree of anaemia. The initially high concentration of benzidine-staining compound in the albumin fraction was almost certainly due to the presence of methaemalbumin, although after haemoglobin additions some of this could have been accounted for by the haemoglobin. The simultaneous return of the Schumm test to normal and the disappearance of this albumin band in the serum after electrophoresis is very much in favour of this hypothesis. The fact that the test with ammonium sulphide after the addition of haemoglobin in vitro remained positive so long as there was any acceptance in the $\beta$ region is strongly suggestive that it is the presence of this $\beta$-globulin-haemoglobin compound which is responsible for the formation of the haemochromogen.

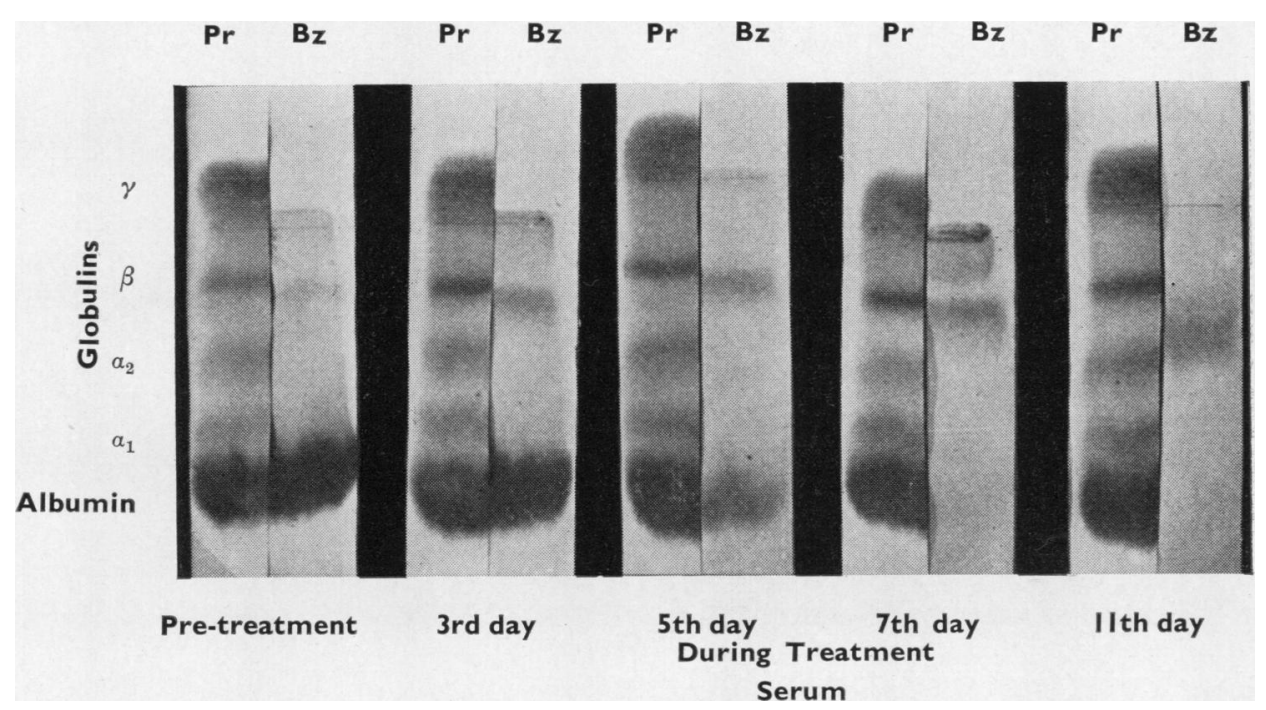

FIG. 7.-Characteristic changes found on electrophoresis of serum from a patient with pernicious anaemia undergoing treatment with vitamin $B_{12}$. Methaemalbumin disappears by the seventh day and haptoglobin reappears by the eleventh day. 
A similar sequence of changes was noted in all the 10 cases of pernicious anaemia successfully treated with vitamin $B_{12}$, although with one exception they showed features of a more chronic rather than an acute haemolytic process.

Identical patterns were also seen in three patients in whom acute intravascular haemolysis had occurred, but who recovered either spontaneously or as a result of therapy, and four cases of acholuric jaundice subjected to splenectomy recovered their normal haemoglobin-protein attachments within seven to 10 days after the operation. In one patient suffering from a chronic haemolytic anaemia of unknown aetiology, splenectomy was undertaken after all other forms of therapy had failed to influence the anaemia. One week after this operation his serum, after adding to it haemoglobin in vitro, gave normal electrophoretic and chemical reactions, but after another week, however, he again showed the pre-operative biochemical abnormalities and a haematological relapse.

In all these patients a constant sequence of events was observed. The benzidine-staining material gradually disappeared from the albumin, and that in the $\beta$ position increased until finally haemoglobin attachment to the $\alpha_{2}$ fraction was detected. This then increased at the expense of the $\beta$-bound component until eventually only the sera containing the higher concentrations of haemoglobin, i.e., 1.2 and $0.6 \mathrm{mg} . / \mathrm{ml}$, showed any staining in the $\beta$ region. The trail of free haemoglobin gradually diminished as these changes in the bound fractions proceeded. The speed of return to normal in treated cases of vitamin $B_{12}$ and folic acid deficiency anaemias favours a central rather than a peripheral haemolytic mechanism in these conditions. It appears that haemolysis must cease very quickly on institution of therapy, a conclusion supported by the rapid fall in serum iron, certainly sooner than would be anticipated if lysis were to continue till the original peripheral cell population was replaced by normal cells. It seems more probable that the time required for cessation of haemolysis is of the same order as that taken for the return to a normoblastic marrow, and this does not seem to be coincidental.

\section{Discussion}

Amongst their multiple functions serum proteins have been shown to play a major role in the transportation of many substances normally found in human blood. Thus, iron was found to be carried by a $\beta_{1}$ globulin (Surgenor, Koechlin, and Strong, 1949 ; Holmberg and Laurell, 1947), trans- port copper is albumin bound (Bearn and Kunkel, 1954 ; Horst, 1954), vitamin $\mathbf{B}_{12}$ was observed to be combined with $\alpha$ and $\beta$ globulin (Latner and Zaki, 1957), and during paper electrophoresis bilirubin migrates with albumin, to mention but some of the known combinations. It is usually assumed that these protein carriers merely hand on their load to the recipient tissues and are then free once more for further use; for example, the serum iron-binding capacity is the same before, during, and after an iron absorption test. However, the most likely explanation for the characteristic changes observed in cases of intravascular haemolysis is that liberation of haemoglobin into the plasma in vivo results in a reduction in the quantity of those plasma proteins with which it combines.

In 1939 Polonowski and Jayle demonstrated that if a small quantity of haemoglobin were introduced intravascularly it appeared to become attached to protein(s) in human plasma, the protein-haemoglobin compound then giving a positive peroxidase reaction. They called this protein haptoglobin and it was later found (Jayle and Abdellatif, 1946) to have a high carbohydrate content. Attention was drawn more recently to the error that it introduced into analysis of electrophoretic strips of haemolysed sera because of the retarding effect that haemoglobin has on $\alpha_{2} \overrightarrow{\vec{B}}$ globulin, resulting in an apparent increase in $\beta$ 응 globulin at the expense of the $\alpha_{2}$ globulin (Wieme, 1953, 1954; Tuttle, 1955). The former author described how with increasing deliberate additions of haemoglobin first one then two bands appeared, ? but these were visible to the eye and were produced by far greater amounts (additions of 4 to 40 $\mathrm{mg}$./ml. serum) than have been used here. These two bands probably represented $\alpha_{2}$ globulin uptake (the haptoglobin of Jayle) and free-moving $\bigcirc$ haemoglobin, but the amount added was too great $\frac{7}{2}$ to have been of value in discriminating between sera from normal individuals and those under- No going haemolysis.

If the primary haemoglobin carrier is the haptoglobin fraction in the $\alpha_{2}$ globulins, as sug- $\omega$ gested by Jayle and Boussier (1955), any condition which caused an increase in the $\alpha_{2}$ globulins might $\stackrel{\circ}{\simeq}$ also increase the ability of the serum to bind $\stackrel{\Phi}{\Phi}$ haemoglobin. Their investigations of sera from patients suffering from acute and chronic infec- $\frac{T}{3}$ tions, malignancy, and disorders in which severe $\frac{\vec{D}}{\mathbb{D}}$

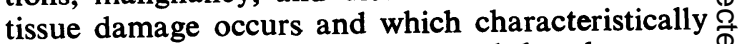
exhibit a rise in $\alpha_{2}$ globulin, showed that these sera $\unrhd$ also accept larger quantities of haemoglobin in that fraction than do sera from normal persons. 


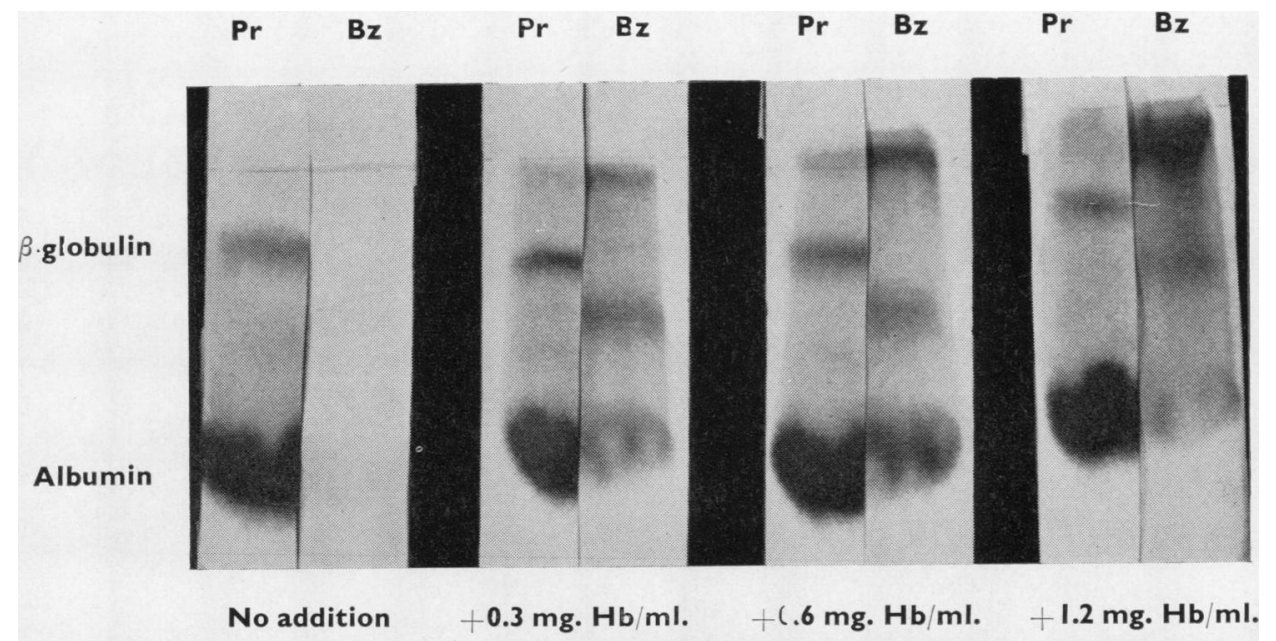

Albumin Preparation

FIG. 8.-Addition of haemoglobin to albumin transfusion preparation, showing presence of an $a_{2}-g$ lobulin binding fraction. Haemoglobin is attached/also to albumin, but does not combine with the $\beta$ globulin in this preparation.

From our own results with normal sera it appears that in different individuals there is sufficient haptoglobin to combine with haemoglobin concentration ranging from about 0.3 to $1.2 \mathrm{mg}$. $/ \mathrm{ml}$. In some control sera where the $\alpha_{2}$ globulin concentration was unusually high, $2.4 \mathrm{mg}$. $/ \mathrm{ml}$. haemoglobin was found insufficient to form more than one electrophoretic band. The high $\alpha_{2}$ globulin concentration which occurs in the nephrotic syndrome did not saturate till even more haemoglobin had been added. Conversely when the concentration of $\alpha_{2}$ globulin is decreased, acceptance of smaller than normal quantities of haemoglobin should be demonstrable, and in the control group one individual was found whose haptoglobin was barely able to carry a concentration of $0.3 \mathrm{mg}$. $/ \mathrm{ml}$.

Once the haptoglobin has been saturated, electrophoresis shows another slightly slowermoving band caused by secondary acceptance by a $\beta$ globulin fraction. This can be shown to be a $\beta_{1}$ globulin by performing the electrophoresis in a buffer containing $20 \mathrm{mg} . / 100 \mathrm{ml}$. calcium ion, which was shown by Laurell, Laurell, and Skoog (1956) to retard the $\beta$ lipoprotein and resolve the $\beta$ globulins into two bands. The usual E.E.L. buffer was employed to which calcium chloride had been added to a concentration of $M / 200$. In an attempt to characterize this fraction further, experiments were carried out with a sample of pure iron-free transferrin,* but no attachment of haematin to this protein was seen. Likewise an albumin transfusion fraction containing $\beta$ globulin

\footnotetext{
* Obtained through the kindness of Professor Schultze, of the Behringwerke, Marburg, Germany.
}

which, by its ability to transport ${ }^{59} \mathrm{Fe}$ was shown to include transferrin, did not contain any $\beta$ haemoglobin-combining protein (Fig. 8). There was, however, evidence of haemoglobin attachment to an ill-defined protein of approximately $\alpha_{2}$ globulin mobility.

Haemoglobin forms a complex with $\beta_{1}$ globulin only after saturating the haptoglobin, but in haemolytic sera this form of attachment is seen with even the minimal addition of $0.3 \mathrm{mg} . / \mathrm{ml}$. and this must, therefore, represent a depletion of haptoglobin. In one or two instances of very severe haemolytic activity it has been possible to show that both the $\alpha_{2}$ and $\beta$ globulins are incapable of binding haemoglobin, and this is further evidence of the hypothesis that in disposing of extracorpuscular haemoglobin the protein attached to it is compulsorily sacrificed, the $\beta$-binding component also having been lost. A similar conclusion is reached with regard to haptoglobin ly Nyman (1957) and Laurell and Nyman (1957), who recently found, using a paper electrophoresis technique similar to our own, that it is absent from sera in cases of pernicious anaemia and returns on treatment with vitamin $B_{12}$. Their conditions of electrophoresis, however, may have caused an overlap of free-moving haemoglobin and the $\beta$ globulins, which could explain how the haemoglobin complex with this fraction has escaped notice. The same may well hold for the report by Liang (1957) that human serum containing haemoglobin exhibits but three bands after electrophoresis, namely, albumin-haemoglobin, $\alpha_{2}$ haemoglobin, and free-moving haemoglobin. 
Although no quantitation was attempted in this series, there appeared to be reduced amounts of $\alpha_{2}$ and $\beta$ globulins even on qualitative inspection of the strips, but it was impossible to make any similar visual assessment of the albumin. It is significant that Christenson and Dacie (1957) have reported a diminution in these fractions in sera of patients who formed warm auto-antibodies.

In the following way it was possible to demonstrate quite clearly that the effects being seen in these sera were due to a serum protein deficiency and not to any peculiarity of the patient's haemoglobin. A constant addition of haemoglobin was maintained throughout a series which consisted of: (1) normal serum and normal haemoglobin, (2) normal serum and patient's haemoglobin, (3) patient's serum and normal haemoglobin, and (4) patient's serum and patient's haemoglobin.

The normal and patient's sera were also $\vec{\circ}$ examined without added haemoglobin. Fig. $9 \overrightarrow{\vec{H}}$

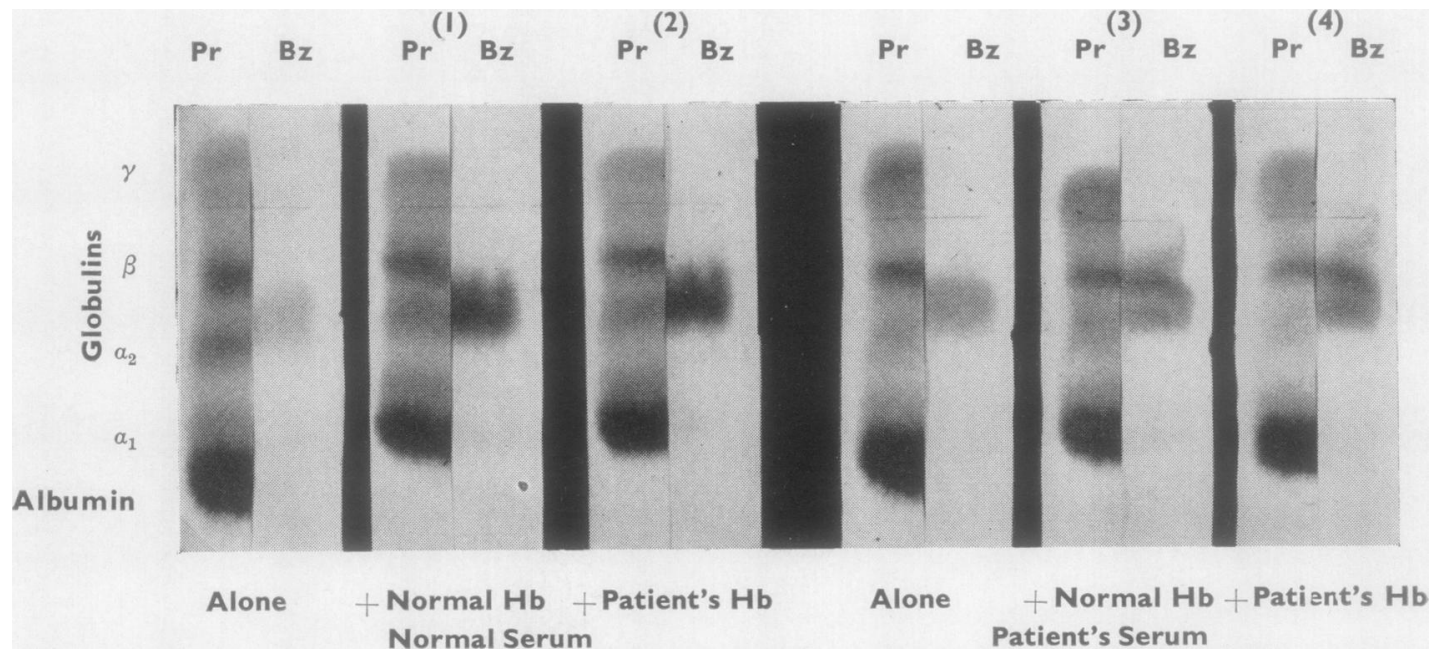

Fig. 9 (a).-Result of electrophoresis of mixtures of haemoglobin and sera from normal individuals and subjects showing haemolysis. Normal serum shows haptoglobin-haemoglobin complex with either haemoglobin; patient's serum exhibits a small amount of haptoglobin-haemoglobin complex and $\beta$ globulin binding.

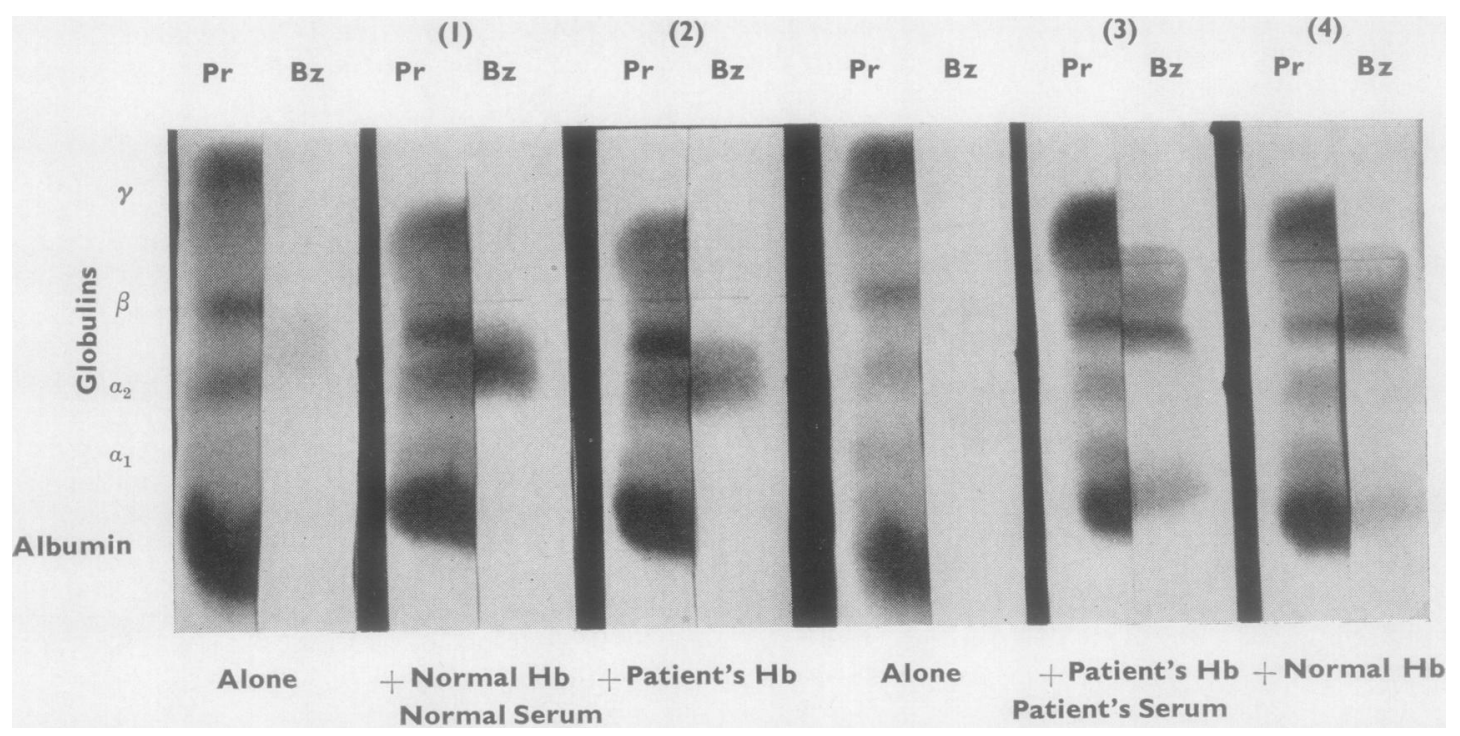

FIG. 9 (b).-Normal serum shows haptoglobin-haemoglobin complex, patient's serum is devoid of haptoglobin, but $\beta$ globulin and albumin binding is seen, also a haemoglobin trail. 
shows the result of electrophoresis. Both (1) and (2) gave a normal result and negative haemochromogen reaction, whereas (3) and (4) gave an abnormal result and positive haemochromogen reaction. Fig. 9 also illustrates typical quantitative differences that are found in sera from individuals showing evidence of haemolysis. In Fig. 9a (3) and (4) is shown haemoglobin attached to a small amount of haptoglobin, to $\beta$ globulin, and a slight trail unattached to protein. Fig. 9b (3) and (4) shows complete absence of haptoglobin binding, but strong $\beta$ globulin and slight albumin uptake. The free-moving haemoglobin is clearly visible behind the $\beta$-globulin-haemoglobin complex. Other sera of this type were tested and similar results obtained. It was also found that if to a serum which gave such abnormal results an equal volume of normal serum was added before the haemoglobin addition, then the mixture reacted as normal serum. These experiments show clearly that a factor, initially lacking, was supplied to the abnormal by the normal serum, and that there must have been in the latter a sufficient quantity of haptoglobin to prevent the mixture giving an abnormal reaction.

Reference has already been made to the appearance of a "haemolytic" pattern in a number of cord bloods taken from normal full-term infants. Tuttle (1955) showed that the sera from newly born babies demonstrated a different haemoglobin-carrying mechanism from that observed in the adult. He found very little haemoglobin attached to the $\alpha_{2}$ fraction but a considerable amount was taken up in the $\beta$ globulin, and that this pattern gradually changed in the first week of life to that normally found in older subjects. It is almost certain that what he was studying was the electrophoretic pattern of increased haemolysis which occurs normally in the early days of life, reflecting the shorter life span of red cells containing foetal haemoglobin. A small number of cord bloods from "Rhesus babies" were also examined and, not surprisingly, showed marked haemolytic patterns.

The Schumm reaction as conventionally employed depends on the production of a haemochromogen from an albumin-haematin complex under the influence of ammonium sulphide. Haematin is also accepted by $\beta$ globulin, but since apparently equally strong, though not preferential, albumin binding always occurs simultaneously in serum, it is not possible on the present evidence to say what part this $\beta$ globulin takes in the classical Schumm reaction. The haemochromogen which is described here appears to derive from the $\beta_{1}$ glo- bulin-haemoglobin complex under the same chemical treatment. This becomes apparent on carrying out both electrophoretic and chemical tests concurrently on a large number of sera. This haemochromogen is produced only when there is sufficient haemoglobin to "spill over" into the $\beta$ globulins. As long as it is all covered by the prime binding protein, haptoglobin, a spectrum of reduced haemoglobin only is seen on ammonium sulphide treatment. Although binding to albumin occurs to a small degree as the haemoglobin concentration is increased, this albumin-haemoglobin complex has probably no part in the haemochromogen reaction, for while formation of an albumin complex may be induced in proteincontaining urine, no haemochromogen is produced unless there is also a $\beta$ globulin linking protein, and this was found in only two of four nephrotic urines examined (Fig. 10). Jayle and Boussier (1954) found that among 31 nephrotic patients examined only one child excreted a significant amount of haptoglobin. If large quantities of the haptoglobin were lost in this way, false positive tests for haemolysis might well complicate the serum studies on these patients. It appears likely that many Schumm reactions that have been reported positive in the past have in fact been contributed to by the haemochromogen reaction now described, as most plasmas in acute haemolytic crises contain in vivo more than sufficient free haemoglobin to provoke it. Also a naturally occurring mixture of haemoglobin and sulphaemoglobin reacted both electrophoretically and with ammonium sulphide exactly as haemoglobin itself.

The fate of these various haemoglobin-protein complexes in the body is not clear, but it appears reasonable to assume that they are removed complete from the blood stream by the reticuloendothelial system, the haemoglobin broken down, and the associated serum protein lost from the circulation.

The two tests described in this paper are always found to be complementary, never contradictory. They are positive only if there is insufficient haptoglobin to bind all the haemoglobin present. In practice it was found that a concentration of $0.3 \mathrm{mg}$. haemoglobin per $\mathrm{ml}$. serum was critical in differentiating normal serum from that of patients experiencing haemolysis. For routine work when there is an adequate sample, the test with ammonium sulphide is quicker to carry out than the electrophoretic technique. When the sample is very small it is then often possible to obtain an answer by electrophoresis without further haemoglobin additions, since it commonly happens that circum- 


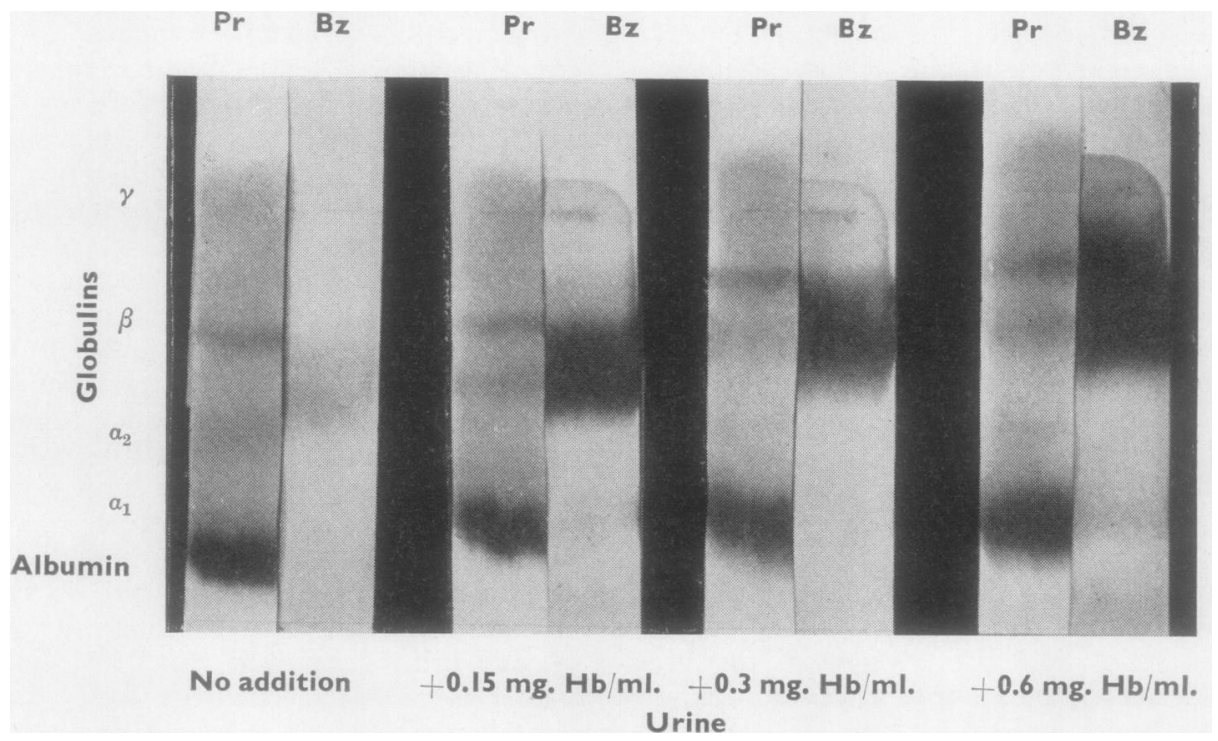

FIG. 10.-Addition of haemoglobin to urine of two patients with the nephrotic syndrome; (a) electrophoresis shows marked haptoglobin, but minimal albumin binding of haemoglobin.

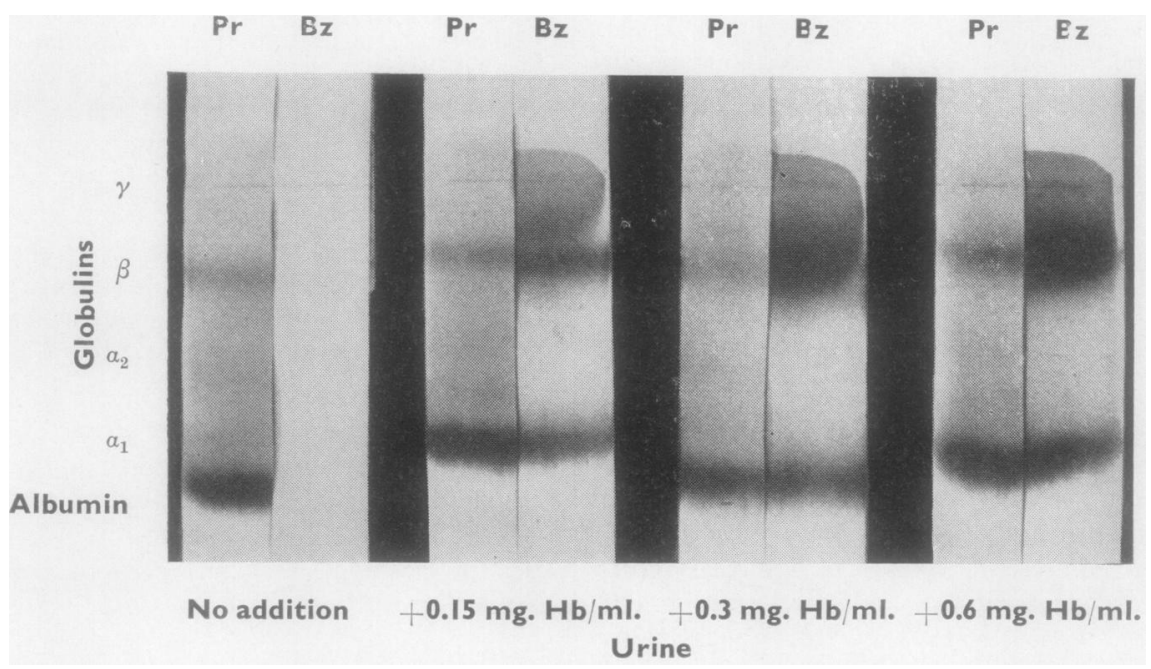

Fig. 10 (b).-Electrophoresis shows albumin and $\beta$ globulin binding of haemoglobin, but no haptoglobin.

stances which preclude a large specimen also result in the introduction of haemoglobin incidental to collection of the specimen. Familiarity with the electrophoretic pattern and experience of depth of staining will often enable one to form an opinion of the probability of haemolysis even under these unfavourable circumstances. For example, if no $\alpha_{2}$ but only $\beta$-globulin binding can be detected, then it is fairly safe to presume that haemolysis has occurred even if the precise amount of added haemoglobin is unknown. Easier still, of course, is the interpretation of a very strong albumin and $\beta$-globulin stain which is most likely to be due to haematin complexes although it may be partly caused by haemoglobin, in which case a trail of this pigment must be visible too. Finally, it seems pertinent to consider that comparable clearance mechanisms may also exist for other plasma constituents and that the haemoglobin disposal system may be but one example of this type. This form of serum transportation, in which the protein is compulsorily lost with its load, appears a novel concept, 
and perhaps applies only where immediate sequestration of a "foreign" protein is essential, and there may be a close analogy between this system and those of the antigen-antibody type. Further examples may be found once the principle is conceded, and these will help to decide whether the haemoglobin interactions are unique or can be better classed as a "transport" or as a "defence" system.

\section{Summary}

Two complementary tests are described which detect intravascular haemolysis and are diagnostic when other simple tests are equivocal or even negative.

These two tests, one electrophoretic, the other purely chemical, are based on a common principle, the mode of haemoglobin attachment to serum protein. Electrophoretic evidence is presented that haemoglobin can form complexes not only with haptoglobin but also with a $\beta$ globulin and albumin.

Application of the tests to a variety of clinical conditions involving haemolysis has shown that disappearance of haemoglobin from plasma is accompanied by loss of its carrier proteins. The implications of this fact are discussed.

Serial investigation of patients with megaloblastic anaemia treated with vitamin $B_{12}$ or folic acid show that haemolysis ceases very soon after institution of therapy and points to a central rather than a peripheral haemolytic mechanism.

The authors wish to express their gratitude to Dr. J. N. Marshall Chalmers for his interest and encouragement throughout this work and for his criticism of the paper, to Professor J. R. Squire for reading the paper, and to $\mathrm{Dr}$. H. G. Kohler for specimens of blood from patients with anaemias of pregnancy.

\section{Addendum}

Since submitting this paper for publication, Allison and ap Rees (1957), using the starch-block electrophoretic technique previously employed by Smithies (1955), have described experiments with serum from normal individuals and from patients in whom haemolysis had occurred. Their results show an acceptance of up to $135 \mathrm{mg}$. haemoglobin $/ 100 \mathrm{ml}$. serum in the normal case, but a marked reduction or complete absence of haptoglobin in the serum of the patients studied. They concluded, in accord with Laurell and Nyman (1957), that both the serum haptoglobin level and tubular reabsorption of haemoglobin together determine the renal threshold for haemoglobin.

\section{REFERENCES}

Allison, A. C., and Rees, W. ap (1957). Brit. med. J., 2, 1137 Bearn, A. G., and Kunkel, H. G. (1954). Proc. Soc. exp. Biol. (N.Y.), $85,44$.

Christenson, W. N., and Dacie, J. V. (1957). Brit. J. Haemat., 3, 153. Durrum, E. L. (1950). J. Amer. chem. Soc., 72, 2943.

Fairley, N. H. (1941). Quart. J. Med., 34 (n.s. 10), 95. and Bromfield, R. J. (1937). Trans. roy. Soc. trop. Med. Hyg., $31,139$.

Fiser-Herman, M., and Davorin, P. (1953). Biochem. Z., 324, 96.

Gattermann, L. (1941). Laboratory Methods of Organic Chemistry, p. 407. Macmillan, London.

Ham, T. H. (1939). Arch. intern. Med., 64, 1271.

Hardwicke, J., and Squire, J. R. (1955). Clin. Sci., 14, 509.

Hawkins, C. F. (1955). Brit. med. J., 1, 383.

Hensley, W. J., and Blackburn, C. R. B. (1953). Aust. J. Sci., 16, 64. Holmberg, C. G., and Laurell, C. B. (1947). Acta chem. scand., 1, 944. Horst, W. (1954). Klin. Wschr., 32, 961.

Jayle, M. F., and Abdellatif (1946). Bull. Soc. Chim. biol. (Paris), 28, 80.

- and Boussier, G. (1954). Ibid., 36, 959.

Kohn, J., and O'Kelly, T. (1955). J. clin. Path., 8, 249.

Latner, A. L., and Zaki, A. H. (1957). Biochem. J., 66, 54p.

Laurell, C. B., and Nyman, M. (1957). Blood, 12, 493.

Laurell, S., and Skoog, N. (1956). Clin. Chem., 2, 99.

Liang, C. C. (1957). Biochem. J., 66, 552.

Neale, F. C. (1955). J. clin. Path., 8, 334.

Nyman, M. (1957). Scand. J. clin. Lab. Invest., 9, 168.

Polonowski, M., and Jayle, M. F. (1939). Bull. Soc. Chim. biol. (Paris), 21, 66.

Schumm, O. (1912). Hoppe-Seyl.Z. physiol. Chem., 80, 1.

Smithies, O. (1955). Biochem. J., 61, 629.

Surgenor, D. M., Koechlin, B. A., and Strong, L. E. (1949). J. clin. Invest., 28, 73 .

Tuttle, A. H. (1955). Science, 121, 701.

Wieme, R. J. (1953). Experientia (B zse!), 9, 380.

- (1954). Rev. belge. Path., 23, 321. 